\title{
MUDANÇA NO ENSINO MÉDIO NO BRASIL ATUAL
}

\author{
Érika Fabíola de Araújo Ribeiro* e Albuquerque, Elenilce Gomes de Oliveira, Antônia de Abreu \\ Sousa, Samuel Brasileiro Filho \\ E-mail: *erikafabiolar@gmail.com \\ Instituto Federal de Educação, Ciência e Tecnologia do Ceará \\ DOI: $10.15628 /$ rbept.2020.9031
}

Artigo submetido em: set/2019 e aceito em: mai/2020

\begin{abstract}
RESUMO
Destaca a reforma do Ensino Médio brasileiro (Lei oㅜ 13.415/2017) em face dos interesses antagônicos de classe na disputa pela Educação, examinando, de um lado, a vertente tradicional de formação de trabalhadores - com ênfase na rotina fatigante das extensas listas de questionários escolares, desestímulo à participação democrática e predomínio de autoritarismos - e, de outra parte, as fragilidades dessa formação para os trabalhadores. A investigação, de cunho bibliográfico, recorreu a autores como Foucault (1999), Enguita (1989), Freire (1987), Mészáros (2008), Saviani (2007), Nosella (2019), Oliveira (2016), Frigotto (2016), Ciavatta (2011), entre outros. Na conclusão, assinala a reforma como evidência da sonegação do conhecimento ampliado ao trabalhador, bem como da formação integral, autonomia e discernimento sociocrítico, restando-lhe o sobejo educativo desconexo e fracionado.
\end{abstract}

Palavras-chave: Educação. Ensino Médio. Capitalismo. Trabalhador.

\section{CHANGE IN HIGH SCHOOL IN CURRENT BRAZIL}

\begin{abstract}
The article aims to highlight the reform of the Brazilian High Scholl (Law 13,415/2017) in the face of antagonistic class interests in the dispute for Education, examing, on the hand, the traditional aspect of worker training - emphasis on the stressful routine of estensive lists os achool questionnaires, discouragement of dramaticparticipation and predominance of authoritarianism - and, on the other, the weaknesses of this training for workers. The research, of bibliographic nature, considered Foucault (1999), Enguita (1989), Freire (1987), Mészáros (2008), Saviani (2007), Nosella (2019), Oliveira (2016), Frigotto (2016), Ciavatta (2011) among others. In the conclusion, he points out the reform as evidence of the evasion of the knowledge extended to the worker, as well as of the integral formation, autonomy and socio-critical discernment, leaving to him the disconnected and fractional educational sobriety.
\end{abstract}

Keywords: Education. High School. Capitalism. Worker. 


\title{
1 INTRODUÇÃO
}

\begin{abstract}
A formação esperada os libertará do padrão de trabalho classista, sexista, racista que rege as relações sociais de produção e de trabalho? Os currículos garantirão o direito a esses saberes? Os fortalecerão a resistir por uma vida justa, humana? Pelo direito a trabalhos humanizantes? (ARROYO, 2018, p. 22).
\end{abstract}

Que feições tem a Educação escolar dos jovens brasileiros, atualmente? Por que essa feitura agrada a algumas frações sociais e não a todas? Em primeiro lugar, é preciso ter claro o fato de que uma sociedade composta por classes sociais requer educação distinta e, por conseguinte, nenhum projeto agradará a todos os segmentos. Expressa a ideia de outro modo, o antagonismo de classe não permite um acordo em torno da Educação escolar, haja vista que a camada trabalhadora almeja a ampliação de vagas nos diversos níveis de ensino, ao passo que a classe capitalista obsta esse alargamento, usando o princípio da meritocracia.

Pressupomos que cada formação histórico-social cria a escola para perpetuála, mas, sendo a realidade contraditória, nela residem, potencialmente, elementos de resistência e contraposição a essa escola. Assim, impõe-se o entendimento acerca de qual a característica da escola que reproduz ou, de outro modo, contribui para transformar a formação histórico-social capitalista, situando a formação da juventude brasileira, na atualidade.

Considerando elucidativo tal discernimento, a primeira parte deste ensaio reporta-se à escola sob o antagonismo de classe, ao passo que a segunda se volve à recente reforma do Ensino Médio, no Brasil, como expressão dessa polaridade e sonegação do direito ao acesso ao conhecimento. Este escrito se louvou nas reflexões de Foucault (1999), Enguita (1989), Freire (1987), Mészáros (2008), Saviani (2007), Nosella (2019), Oliveira (2016), Frigotto (2016), Ciavatta (2011), entre outros. Concluise que a feição da Educação escolar brasileira é constituída pelos contornos da disputa em torno da Educação integral e emancipatória, de um lado, e da educação unilateral e tradicional, de outra vertente.

\section{A ESCOLA NO CAPITALISMO}

A instituição escolar, tal como se conhece nos dias atuais, não se caracteriza como um espaço de aprendizado que esteve presente em todas as épocas e sociedades. A formação para o trabalho não se dava necessariamente dentro deste ambiente. 
Saviani (2007) considera que a formação para o trabalho coincide com a formação do ser humano, uma vez que, para sobreviver, diferente dos outros animais que se adaptam à natureza, o Homo sapiens moderno aprende a transformá-la, adaptando-a às suas necessidades. Logo, a formação humana é um processo educativo, e suas origens, bem como as da Educação, fazem parte do mesmo fenômeno.

\begin{abstract}
Se a existência humana não é garantida pela natureza, não é uma dádiva natural, mas tem de ser produzida pelos próprios homens, sendo, pois, um produto do trabalho, isso significa que o homem não nasce homem. Ele forma-se homem. Ele necessita aprender a ser homem, precisa aprender a produzir sua própria existência. Portanto, a produção do homem é, ao mesmo tempo, formação do homem, isto é um processo educativo. A origem da educação coincide, então, com a origem do homem mesmo. (SAVIANI, 2007, p.154).
\end{abstract}

Na manufatura, por exemplo, os artesãos e camponeses aprendiam seu ofício com seus pais e avós e os transmitiam para seus filhos e netos, sendo a família a instituição responsável pela formação para o mundo do trabalho e pela sociabilidade de suas crianças e jovens. Era comum o envio de crianças ainda pequenas para lares de outras famílias, onde, além de aprenderem um ofício distinto daquele ensinado em seu grupo familial de origem, aprendiam também boas maneiras e a realizar atividades domésticas. (ENGUITA, 1989).

O objetivo daquilo que Mariano Enguita (1989) chama de "intercâmbio familiar" não se resumia ao aprendizado de mais um ofício ou de boas maneiras, mas "[...] a criança que é enviada como aprendiz-servente a outra família está aprendendo [...] as relações sociais de produção" (p. 107), o que não seria possível no seio de suas famílias, uma vez que os laços de afetividade poderiam interferir na disciplina.

Com a estruturação do sistema capitalista de produção, capitalistas perceberam a necessidade de inserir um sistema formal de ensino no contexto social, visto que a família e os grupos sociais das crianças e dos jovens já não eram capazes de transmitir os conhecimentos necessários para a consolidação do modo de produção emergente.

A necessidade de mão de obra livre que correspondesse às expectativas do novo padrão de produção encontrou dificuldades de aceitação junto aos trabalhadores independentes (camponeses e artesãos). Estes, acostumados com a economia de subsistência, em que decidiam o que, quando, como e em que ritmo produzir, não se sentiram atraídos pela técnica de produção imposta pela indústria, apesar da promessa de ascensão social por meio de salários maiores (ENGUITA, 1989).

A transição da manufatura para a produção industrial não ocorreu sem resistências e conflitos entre os estratos trabalhadores e os capitalistas. Camponeses 
e artesãos, coagidos a desenvolver atividades laborais em ambiente distinto ao do lar, empreenderam grande energia na tentativa de burlar as normas impostas nas fábricas, manifestas por meio das faltas excessivas, do alcoolismo e mediante pequenas sabotagens (ENGUITA, 1989).

Em razão de problemas referentes à pouca adaptação dos trabalhadores ao novo modelo de trabalho e ao comportamento dos operários, capitalistas perceberam que era preciso formar trabalhadores desde a mais tenra idade, para atender às exigências do novo modo de produção. O exército foi uma das primeiras instituições para onde crianças eram encaminhadas, pois lá recebiam treinamento dentro do rigor da disciplina e da obediência. "Depois de tal experiência, o mais embrutecedor dos trabalhos pode ser visto como uma liberação". (ENGUITA, 1989, p. 30). A experiência militar, contudo, era curta e pouco rentável, além de não alcançar o público feminino, o que a tornou não muito atraente aos interesses do capital. Dessa maneira,

\begin{abstract}
Era preciso inventar algo melhor, e inventou-se e reinventou-se a escola; criaram-se escolas onde não havia, reformaram-se as existentes e nelas se introduziu à força toda a população infantil. A instituição e o processo escolares foram reorganizados de forma tal que as salas de aula se converteram no lugar apropriado para acostumar-se às relações sociais do processo de produção capitalista, no espaço institucional adequado para preparar as crianças e os jovens para o trabalho. (ENGUITA, 1989, p. 31).
\end{abstract}

Desde então - assevera Saviani (2007) - desenvolveu-se uma modalidade específica de educação, diferente daquela do processo produtivo, transferindo-se para a escola a tarefa educativa, descolando-a das atividades de produção, dando origem à dualidade na Educação.

\footnotetext{
Essa separação entre escola e produção reflete, por sua vez, a divisão que se foi processando ao longo da história entre trabalho manual e trabalho intelectual. Por esse ângulo, vê-se que a separação entre escola e produção não coincide exatamente com a separação entre trabalho e educação. Seria, portanto, mais precioso considerar que, após o surgimento da escola, a relação entre trabalho e educação também assume uma dupla identidade. De um lado, continuamos a ter, no caso do trabalho manual, uma educação que se realiza concomitantemente ao próprio processo de trabalho. De outro, passamos a ter a educação de tipo escolar destinada à educação para o trabalho intelectual. (SAVIANI, 2007, p. 157).
}

O surgimento da instituição escolar formal está associado ao desenvolvimento do sistema de produção capitalista, o qual necessitava de trabalhadores minimamente qualificados nas funções de ler, escrever e contar, para o manuseio do maquinário. A escola foi, então, utilizada pelos grupos hegemônicos não apenas para repassar esses ensinamentos, mas também (e principalmente) para disseminar a ideologia 
dominante, preparando futuros trabalhadores dentro de normas de condutas e valores do capital. " $E$ a via para o cumprimento desse papel reprodutor é o desenvolvimento da escola como uma instituição apartada do trabalho produtivo". (SAVIANI, 2007, p. 157).

O adensamento de crianças proletárias nas escolas não implicou, obviamente, que usufruíssem da mesma educação destinada às elites - desenvolvimento de habilidades da gestão e planejamento, às quais requerem largo domínio teórico. A negação do direito ao saber à classe trabalhadora foi escamoteado pelo acesso à formação prática, aligeirada, limitada, segmentada, distanciada do seu contexto social, político, econômico e cultural, prejudicando a formação de cidadãos críticos, reflexivos e conscientes do pertencimento de classe.

Vale ressaltar que a Educação tem duplo e antagônico papel, pois, ao mesmo tempo em que é um dos mecanismos responsáveis pelo ato de reproduzir e conformar as pessoas à ordem social vigente, também tensiona as estratégias edificadas pela classe capitalista. Mészáros (2008) alerta para o fato de que, sozinha, a educação não é capaz de realizar transformações sociais profundas, mas pode contribuir para a tomada de consciência e pertencimento de classe, que seria o primeiro passo a ser dado.

No âmbito da Educação tradicional, contudo, crianças e jovens são depositados nos bancos escolares por quatro ou cinco horas, recebendo, de maneira verticalizada, o conteúdo acompanhado da formação de atitudes e comportamentos passivos ou ativos. Essa modelagem foi exaustivamente criticada por Freire (1987), por se assemelhar ao sistema bancário, em que as informações são depositadas, sem considerar o contexto sociopolítico, econômico e histórico do estudante, tampouco incentivá-lo a articular um pensamento crítico e reflexivo perante sua realidade social.

É possível perceber intensa semelhança entre as escolas de caráter tradicional e a fábrica, sobretudo porque aos discentes é negado o direito de definir ou elaborar - junto com o professor - os conteúdos que tencionam aprender, assim como o poder de definir o que produzir - e como o fazer - foi retirado do trabalhador.

A posição do aluno diante do saber e diante da relação em que se colocou com ele é tão contemplativa e passiva como a do trabalhador diante da produção social e do lugar que nela se lhe atribuiu. (ENGUITA, 1989, p. 200).

A escola tradicional se assemelha ao estabelecimento fabril, haja vista 0 sistema de recompensas adotado em ambos. Enquanto a escola promete (mas não tem forças para cumprir, pois depende do mercado para isso) a ascensão social e os melhores empregos para os mais dedicados, a fábrica recompensa seus empregados mediante o pagamento de salários, das gratificações ou da promessa na participação nos lucros. 
Assim, para atender à demanda do sistema de produção por trabalhadores cada vez mais produtivos e submissos, as escolas tradicionais burguesas educam no sentido de esculpir futuros trabalhadores, ajustando seus comportamentos, reprimindo seus desejos e vontades, controlando seus gestos e atitudes e docilizando seus corpos. Logo,

[...] não se trata de cuidar do corpo [...] como se fosse uma unidade indissociável, mas de trabalhá-lo detalhadamente; de exercer sobre ele uma coerção sem folga, de mantê-lo ao nível mesmo da mecânica - movimentos, gestos atitude, rapidez: poder infinitesimal sobre o corpo ativo. [...] Esses métodos que permitem o controle minucioso das operações do corpo, que realizam a sujeição constante de suas forças e lhes impõem uma relação de docilidade-utilidade, são o que podemos chamar as "disciplinas". (FOUCAULT, 1999, p. 118).

Enguita (1989) assevera ser essa a função primeira da escola, uma vez que crianças e jovens assimilam regras do disciplinamento e da ordem, antes mesmo do conteúdo escolar. Cercados pelos muros do colégio, onde passam muitas horas de seu dia, os estudantes logo percebem que devem obedecer e respeitar os horários de entrada, saída e intervalo. Todo o tempo do aluno é preenchido por atividades desenvolvidas nos mais diversos locus escolares. Cada ambiente tem a própria funcionalidade: as salas são destinadas ao aprendizado teórico, os laboratórios às atividades práticas e, ao intervalo, é designada uma pequena parcela do tempo, pois, quando se trata de moldar comportamentos, não há tempo a perder. Os discentes são enfileirados nas salas e, no pátio, "[...] cada indivíduo em seu lugar e em cada lugar um indivíduo" (FOUCAULT, 1999, p. 123), de onde são cuidadosamente vigiados pelo olhar atento dos agentes escolares, sendo facilmente identificadas suas presenças $e$ ausências.

Importa estabelecer as presenças e as ausências, saber onde e como encontrar os indivíduos, instaurar as comunicações úteis, interromper as outras, poder, a cada instante vigiar o comportamento de cada um, apreciálo, medir as qualidades ou os méritos. Procedimento, portanto, para conhecer, dominar e utilizar. A disciplina organiza um espaço analítico. (FOUCAULT, 1999, p. 123).

$\mathrm{Na}$ escola tradicional, a pessoa e suas singularidades desaparecem e dão lugar ao aluno ou, nas palavras de Enguita (1989), a infância cede espaço para a "alunância". É mais um estudante, no universo de multiplicidades, que precisa ter o comportamento padronizado, normalizado, ao mesmo tempo em que suas competências individuais precisam ser medidas e avaliadas. 
Aparece, através das disciplinas, o poder da Norma. [...] O Normal se estabelece como princípio de coerção no ensino, com a instauração de uma educação estandardizada e a criação das escolas normais: estabelece-se no esforço para organizar um corpo médico e um quadro hospitalar da nação capazes de fazer funcionar normas gerais de saúde, estabelece-se na regularização dos processos e dos produtos industriais. Tal como a vigilância e junto com ela, a regulamentação é um dos grandes instrumentos de poder no fim da era clássica. As marcas que significavam status, privilégios, filiação, tendem a ser substituídas ou pelo menos acrescidas de um conjunto de graus de normalidade, que são sinais de filiação a um corpo social homogêneo, mas que têm em si mesmos um papel de classificação, de hierarquização e de distribuição de lugares. Em certo sentido, o poder de regulamentação obriga à homogeneidade; mas individualiza, permitindo medir os desvios, determinar os níveis, fixar as especialidades e tornar úteis as diferenças, ajustando-as umas às outras. (FOUCAULT, 1999, p. 153,154).

Os alunos aprendem a ser passivos, a adiar sua satisfação e sufocar seus desejos em nome de normas, regulamentos e rotinas. Perdem as identidades para viver em coletividade, ao mesmo tempo em que são o individualismo e a competição reforçados, por meio das provas. "A competição é estimulada, sobretudo, através das notas [...]. A publicação de cada nova rodada de notas supõe uma relocalização simbólica dos indivíduos dentro do grupo". (ENGUITA, 1989, p. 197).

A organização serial, de acordo com a idade biológica, estabelecida na escola tradicional, possibilita ao professor o controle e classificação de cada estudante e o envolvimento de todos em atividade única, além de permitir que a escola se torne, não somente, uma "[...] máquina de ensinar, mas também de vigiar, de hierarquizar, de recompensar. (FOUCAULT, 1999, p. 126). O conteúdo e os processos avaliativos são padronizados em uma sequência cujo nível de dificuldade se eleva paulatinamente no decurso dos anos.

Para Enguita (1989), a passagem da escola unidocente ${ }^{1}$ para a seriada estimulou a competição e o individualismo.

Reunindo todos os alunos por idades escolares associadas à idade biológica e separando-os em maiores e menores, propiciou a padronização dos critérios de avaliação e organizou a competição em torno deles. (ENGUITA, 1989, p. 199).

\footnotetext{
1 "Nas primeiras [escolas], a diversidade de níveis juntava alunos de diferentes idades, entre os quais não tinha sentido uma relação competitiva, e o próprio professor, para uma maior eficácia ou para aliviar sua carga, fomentava uma relação de colaboração (o apoio dos maiores aos de menor idade e dos mais avançados aos atrasados". (ENGUITA, 1989, p. 199).
} 
Esse formato de organização, além de homogeneizar o aprendizado ${ }^{2}$, possibilita 0 acirramento da competição, porquanto todos (ou a maioria) miram o mesmo horizonte (os melhores empregos), que supostamente só será alcançado pelos que se destacarem, ou seja, aqueles com as melhores notas ou os maiores títulos.

A separação serial e o acirramento da competição, especialmente por meio do sistema de notas, fragilizam as relações que os estudantes estabelecem entre si. $O$ distanciamento e as relações superficiais impedem o surgimento de afinidades e formação de identidades de grupos. Socializar hoje os alunos no individualismo e na competição significa, no futuro, minar o poder de organização da classe trabalhadora perante os empregadores, além de obstaculizar a formação de identidade e pertença de classe (ENGUITA, 1989).

A estratégia adotada pelo grupo hegemônico é de desarticulação e manipulação da pessoa, por meio de uma educação que ressalta a cultura dominante como superior às demais, contraposta à educação libertadora sugerida por Paulo Freire, a qual sugere que a superação da circunstância de submissão da classe trabalhadora se dará por meio da tomada de consciência de classe, que é possível mediante a cooperação entre as pessoas.

Aquilo que poderia ser a luta de classes, com vistas à igualdade social, pode se transformar em peleja individual para transformação da realidade de cada cidadão, que se vê gradativamente familiarizado com os termos meritocracia e individualização, interiorizando o seu destino - sina - como responsabilidade pessoal (ENGUITA, 1989). A escola tradicional, por sua vez, pode contribuir para reforçar esse discurso, na medida em que se expressa como corresponsável pelos sucessos, e se exime de responsabilidades quando se registra fracasso, corroborando a lógica mercadológica, a qual transfere unicamente para o trabalhador a responsabilidade por seus maus êxitos sociais, sem deixar transparecer a incapacidade do sistema de absorver toda a mão de obra disponível.

As cercas - muros; o cumprimento de horários; a distribuição espacial; a perda de singularidade; a homogeneização de atitudes; a padronização de condutas e processos; a avaliação de comportamentos e competências; a classificação; a passividade e submissão; a repressão dos desejos e vontades em nome da norma; o individualismo e competição; a meritocracia, a organização serial e a obsessão pelo silêncio; o interdito de circulação; e a vigilância atenta em curso na escola tradicional - tudo isso pode ser encontrado, também, nas fábricas e em outras instituições - como prisões, hospitais e quartéis. Trabalhadores são treinados - ou, nas palavras de Foucault (1999), adestrados - durante anos de suas vidas, em ambiente similar ao que encontrarão nos espaços de trabalho, para que sejam capazes de exercer suas atividades com a maior eficiência, eficácia e efetividade, sem causar grandes

\footnotetext{
${ }^{2}$ Em princípio, crianças e jovens na mesma faixa etária expressam necessidades semelhantes.
} 
contratempos ao capital, para que sejam condescendentes com sua posição social, uma vez que, se a escola conseguiu êxito com uns, não justifica que outros não obtenham o mesmo sucesso, a menos que não tenham essas pessoas se esforçado o suficiente para que, por méritos próprios, fossem capazes de mudar suas posições sociais.

A escola tradicional burguesa, portanto, pode se configurar como espaço disciplinador e hierárquico, onde as relações de poder se expressam por meio do controle e da excessiva vigilância, seja ela direta, por meio da equipe de profissionais, ou indiretamente, por via dos regulamentos e normas.

\begin{abstract}
A escola não é uma prisão, mas assim como a prisão ela é feita com base em um conjunto de regras; ela é disciplinar e antidisciplinar, ela guarda em si o panóptico ${ }^{3}$, que tenta controlar, e o antipanóptico, que tenta resistir [...] (ANDRADE, 2012, p. 147).
\end{abstract}

Nesse sentido, Silva, et al (2018) afirmam que a Educação não transforma a sociabilidade humana, mas é transformada pela sociedade, de acordo com suas necessidades e períodos históricos. No entanto, não se pode afirmar que a escola burguesa, tradicionalmente, desempenha o papel de conformação social sem ser alvo de grandes resistências dos grupos sociais. Embora os grupos hegemônicos tenham se empenhado em garantir a escola como um meio de dominação e poder, a classe trabalhadora tenta reagir na mesma intensidade, impondo resistência ao modelo tradicional e ocupando os espaços para discussão e controle social, revelando-a como um mecanismo indispensável, por intermédio do qual é possível realizar a transformação social. A instituição escolar torna-se, dessa maneira, um espaço onde as disputas de projetos ideológicos distintos se confrontam.

Que a escola tradicional surge atrelada à emergência do modo de produção capitalista e vem sendo, no decorrer dos anos, a instituição mais eficiente (ao lado da família) no sentido de propagar a ideologia dominante, não se pode negar. Ao passo,

\footnotetext{
3"O princípio é conhecido: na periferia uma construção em anel; no centro, uma torre; esta é vazada de largas janelas que se abrem sobre a face interna do anel; a construção periférica é dividida em celas, cada uma atravessando toda a espessura da construção; elas têm duas janelas, uma para o interior, correspondendo as janelas da torre; outra, que dá para o exterior, permitindo que a luz atravesse a cela de lado a lado. Basta então colocar um vigia na torre central, e em cada cela trancar um louco, um doente, um condenado, um operário ou um escolar. Pelo efeito de contraluz, pode-se perceber da torre, recortando-se exatamente sobre a claridade, as pequenas silhuetas cativas nas celas da periferia.[...]. Daí o efeito mais importante do Panóptico: induzir no detento um estado consciente e permanente de visibilidade que assegura o funcionamento automático do poder. [...] o detento terá diante dos olhos a alta silhueta da torre central de onde é espionado [...] (ele) nunca deve saber se está sendo observado; mas deve ter certeza de que sempre pode sê-lo. O Panóptico é uma máquina de dissociar o par verser visto: no anel periférico, se é totalmente visto, sem nunca ver; na torre central, vê-se tudo, sem nunca ser visto". (FOUCAULT, 1999, p. 165,167).
} 
contudo, em que a escola possui essa característica, ela é, também, responsável por estimular nas pessoas um pensamento crítico e reflexivo ante a realidade em que elas se inserem, possibilitando uma formação da autonomia e a real liberdade dos cidadãos, elementos indispensáveis para superar o estado de submissão dos trabalhadores.

Educação e escola pressupõem conhecimento e instrução e, por conseguinte, ultrapassam os limites do aprisionamento e vigilância, transformando-se, dialeticamente, no seu contrário. $O$ conhecimento permite também a edificação de críticas, julgamentos e, por isso, autoconhecimento social e histórico, consciência de si e de sua relação com o mundo (NOSELLA, 2019).

É nesse sentido que o próximo tópico aborda a correlação de forças em torno da recente reforma do Ensino Médio no Brasil, evidenciando seus impactos sociais para a Educação, especialmente àquela ofertada para a classe trabalhadora, alargando o fosso já existente entre a formação destinada às diferentes camadas sociais, que nega aos trabalhadores o direito ao saber crítico, reflexivo e articulado com sua realidade social. Essa reforma constitui uma das distintas e inúmeras janelas que contribuem para o efeito panóptico, auxiliando o sistema de controle sobre o saber do trabalhador, extirpando o direito ao amplo saber.

\section{O CONTROLE DO SABER POR INTERMÉDIO DA REFORMA DE ENSINO MÉDIO NO BRASIL}

Inspirada nos apaixonados ideários político-filosóficos, democráticos e libertários de origem europeia, as primeiras escolas de tempo integral, construída em solo brasileiro, foram inauguradas, segundo Branco (2012), pelo secretário de Educação da Bahia, Anísio Teixeira, em 1950. O acesso ao saber incluía desenho, música, dança, educação física, leitura, aritmética, ciências físicas e sociais e artes industriais, ou seja, unia o ensino ao trabalho. Além disso, o estudante detinha um suporte singular: alimentação e atendimento em consultório odontológico e médico no interior da escola.

Esse modelo de escola pressupõe um Estado fortemente inclinado ao fortalecimento de políticas sociais, assegurando, sobremaneira, os serviços essenciais à população. A feitura dessa tipologia de Estado depende das correlações de forças sociais, cujo embate reverberam na inclinação do pêndulo das balanças da Economia e dos direitos sociais. Com efeito, repercutem na robustez ou arrefecimento de políticas educacionais de interesse dos trabalhadores.

No Brasil, as escolas de tempo integral somente se tornaram política pública por intermédio da Lei 10.172/2001, que instituiu o Plano Nacional de Educação (PNE) referente ao período 2001 a 2010. O estabelecido em seus objetivos conferiu prioridade de ensino fundamental às crianças de 7 a 14 anos, com prioridade de tempo 
integral para as crianças mais pobres (BRASIL, 2001). O atual PNE, Lei 13.005/2014, estabeleceu em sua meta 6 a oferta de "[...] educação em tempo integral em $50 \%$ das escolas públicas de educação básica" (BRASIL, 2014).

Recentemente, a pretexto de instituir a Política de Fomento à Implementação de Escolas de Ensino Médio em Tempo Integral, o Governo Federal obteve a conversão da medida provisória 346/2017 em Lei, instituindo, dessa maneira, a Lei no 13.415/2017, conhecida como a Reforma do Ensino Médio.

Propagandas veiculadas pelo Governo Federal nos meios de comunicação, à época, ressaltavam ser o maior propósito dessa mudança propiciar liberdade ao estudante para escolha do conteúdo, consoante às suas intenções. Na contramão desse marketing, diversos ensaios, cartas e manifestos - Oliveira (2016); Mota e Frigotto (2017); Costa e Coutinho (2019); Cavalcanti (2018); Araújo e Silva (2017), Callegari (2018); Ferretti (2018); ANDES (2017), CNTE (2017), ANPOCS (2018); ANFOPE (2018), SINSEJ (2018); SINPRO (2017) entre outros - acentuaram princípios e aspectos problemáticos.

Não obstante, trata-se da precarização da Educação Básica. Disciplinas como História, Geografia, Sociologia, Artes, Educação Física, Ciências da Natureza, dentre outras, deixaram de fazer parte da Base Nacional Comum Curricular (BNCC) para o Ensino Médio, na qual, em sua última versão, aprovada pelo Conselho Nacional de Educação (CNE), em dezembro de 2018, constam apenas três disciplinas obrigatórias - Língua Portuguesa, Matemática e Língua Inglesa.

Oliveira (2016) alerta para o fato de que a positividade do discurso da liberdade de escolha, neste caso, ofusca aspectos essenciais dessa reforma, entre eles 0 fracionamento da Educação dos jovens e, por conseguinte, o desvio da cultura geral, a escassez de referências explicativas das questões sociais, entre outras. A referida lei tem como objetivo principal o direcionamento único

[...] da educação escolar dos jovens. Esse aspecto, por si, corrói as possibilidades de uma personalidade vigorosamente formada, asfixiando, no Ensino Médio, as diversas inclinações que coexistem em nós, desequilibrando o ajuste das capacidades intelectivas e práticas [...]. Dessa maneira, limita a experiência formativa, desencoraja o pensamento autônomo e compromete a capacidade de compreensão e intervenção na realidade. (OLIVEIRA, 2016, p. 185-186).

Acreditamos, então, que as escolas públicas terão dificuldades em ofertar os cinco itinerários formativos, em razão de limitações de orçamento e de equipe profissional, além da pouca ou inexistente infraestrutura, especialmente para montar os laboratórios. Com efeito, essas escolas optarão por oferecer apenas os itinerários 
formativos de acordo com a disponibilidade de profissionais habilitados para atuação naquele percurso específico.

[...] atualmente somente $15,7 \%$ dos municípios têm condições de ofertar os cinco itinerários formativos, o que demonstra a falácia propagada pelo governo de que os jovens poderão escolher o itinerário formativo que quiser cursar, quando na verdade serão obrigados estudar o que o município em que residem tiver condições de ofertar. (LIMA; MACEL, 2018, p. 17).

Vê-se que a afirmação de que o estudante poderá escolher as disciplinas com maior afinidade e interesse profissional visa a manipular a opinião pública. A "escolha", longe de ser uma oportunidade para o discente, dependerá das vagas ofertadas pelo sistema de ensino, o que reforça a perda de autonomia do estudante.

Outra consequência importante é a desvalorização dos profissionais do magistério, mormente o adensamento ao notório saber "[...] para ministrar conteúdos de áreas afins à sua formação ou experiência profissional”. (BRASIL, 2017). Tal medida esvazia o concurso público, abrindo caminhos para o retorno do apadrinhamento e paternalismo e reforçando a precarização e terceirização dos docentes.

A reforma estabelece, ainda, o tempo integral, que consiste na ampliação da permanência diária do estudante na escola, saindo de quatro para sete horas de duração. Esse alargamento não implicou a integralidade da formação, mas a sua parcelarização, mediante ausência de bases formativas sociais, filosóficas e artísticas, restando-Ihes conteúdos fracionados e desconectados da realidade.

Assim, corroboramos a ideação de Ramos e Frigotto (2016), quando assinalam que

Os filhos da classe trabalhadora, portanto, na melhor das hipóteses, terão acesso ao ensino médio mínimo, com uma formação mínima para uma vida igualmente mínima. Trata-se de uma política centrada na cultura do fragmento e do imediato, na economia do mínimo e na responsabilidade transferida para uma instância abstrata e volátil que é o mercado. (RAMOS; FRIGOTTO, 2016, p. 42).

\footnotetext{
${ }^{4}$ O notório saber dispensa a necessidade de formação específica e consistente para atuar na docência das disciplinas dos percursos formativos, desconsiderando a importância de uma formação adequada, especialmente em nível superior.
} 
A essa reforma, entre outras que influenciam a educação (a exemplo da PEC $241^{5}$ ), contrapuseram-se parcelas dos estudantes, mediante ocupação de escolas e universidades públicas. As manifestações tiveram início em outubro de 2016, por iniciativa dos secundaristas, ganhando forças e adeptos em todo o País (inclusive de docentes), chegando à ocupação de mais de $1100^{6}$ escolas em 22 estados brasileiros e no Distrito Federal.

A maneira autoritária como a reforma foi aprovada - por meio de Medida Provisória, sem o amplo debate junto à sociedade e sem dialogar com os jovens da classe trabalhadora brasileira (os mais afetados por ela) - demonstra a necessidade da burguesia de retomar os caminhos da Educação tradicional - que nunca deixou de existir, mas não ganhou forças em governos populares - e, principalmente, o "[...] medo de que a luta exemplar dos estudantes secundaristas nas ocupações e de outros movimentos se amplie". (MOTTA; FRIGOTTO, 2017, p. 367).

\begin{abstract}
O momento brasileiro é de uma crise aguda que insere medidas econômicas e políticas ofensivas que afetam fundamentalmente nossos muitos milhares de jovens da classe trabalhadora. $E$ as Jornadas de Junho e as ocupações das escolas e universidades públicas indicam que irrompeu a luta de classes. Com isso, as burguesias dominantes asseveram os mecanismos de controle social por meio dos vários aparelhos de Estado em "união pessoal" com seus respectivos aparelhos privados de hegemonia e com organismos internacionais, introduzem um conjunto de políticas públicas que conformam a conjuntura [...] e buscam cimentar a ideologia necessária para se consolidarem no poder e salvaguardarem os ganhos capital. Por esse motivo, torna-se determinante introduzir reformas na educação - ressaltamos, pública -, na qual se situa a grande massa de jovens da classe trabalhadora para administrar a "questão social" e criar as condições favoráveis para a expansão do capital. (MOTTA; FRIGOTTO, 2017, p.365).
\end{abstract}

Entendemos, portanto, que a Lei no 13.415/2017 em nada avança com vistas a oferecer uma educação capaz de formar cidadãos críticos e propositivos, no objetivo de superar a alienação do capital. Contraposto a essa formação, verifica-se o aprofundamento da dicotomia entre os pares teoria/prática, Educação propedêutica/Educação profissional, em que a Educação, segmentada e apartada do cotidiano das pessoas, é disponibilizada com o pretexto de atender às demandas do mercado, em detrimento da procura por parte da classe trabalhadora, seguindo ideologia semelhante aos princípios que nortearam o surgimento da escola tradicional.

\footnotetext{
${ }^{5}$ A PEC 241(ou PEC 55) congela os gastos públicos em vinte anos. Foi promulgada em 15 de dezembro de 2016 como Emenda Constitucional 95, alterando a Constituição Federal de1988 e tornando-se lei.

6 De acordo com o site https://exame.abril.com.br/brasil/o-mapa-das-ocupacoes-de-escolas-efaculdades-contra-temer/. Acesso em 24 de setembro de 2019.
} 
Trata-se, pois, de ênfase à formação restrita para o trabalho, em detrimento de uma educação pública, ampla, sólida, gratuita e de qualidade referenciada. De acordo com Ciavatta (2011), a dominância da formação profissionalizante, ao longo do século $\mathrm{XX}$, e a manutenção do foco das lutas dos trabalhadores nas melhorias das condições de trabalho contribuíram para a escusa da educação geral do trabalhador.

Um dos maiores desafios aos líderes das entidades associativas dos trabalhadores é, por conseguinte, incorporar a Educação como pauta relevante na sua agenda, uma vez que o conhecimento e instrução enredam-se, consoante Nosella (2019), com a tomada de consciência, contribuindo para a cultura extrema, ou seja, para o autoconhecimento, o julgamento de fatos, etc.

Compreendemos a Educação como uma política pública e um direito de todos, e a escola como um espaço democrático ${ }^{7}$, compulsório ${ }^{8}$ e perpassado por interesses de classes sociais antagônicas, onde são materializados os conflitos ensejados pelo capital. Esse entendimento reforça a necessidade de tensionar as relações sociais, de modo a garantir o direito a uma "[...] educação como recurso de leitura e compreensão do mundo e de emancipação de todas as formas de opressão". (CIAVATTA, 2011, p.170).

Afinal, não obstante a focalização da luta dos trabalhadores brasileiros por melhorias das condições de trabalho, é importante para a classe trabalhadora "[...] conhecer, aprender, desenvolver suas habilidades, ter acesso a melhor e mais ampla bagagem de cultura". (NOSELLA, 2019, p. 24).

Asseveramos, por fim, que a aposta na edificação do preparo emancipatório no interesse da juventude trabalhadora brasileira requer uma escola dotada de: a) atividades integradoras, criativas e estimuladoras; $b$ ) investimentos para a valorização dos profissionais da Educação; c) infraestrutura digna; d) prática de esportes; e) expressão pelas artes; f) valorização dos saberes das minorias; $g$ ) multiplicação de áreas de conhecimento; h) compreensão de si e do mundo; i) acolhimento e respeito às diferenças; j) integração de trabalho mental e manual; I) formação libertadora das opressões.

\section{CONSIDERAÇÕES FINAIS}

A formação tradicional aglutina interesses da classe dominante capitalista. Esse ambiente fechado e controlado funciona como uma espécie de laboratório, onde os comportamentos dos estudantes são observados e avaliados a todo o momento, onde crianças e jovens são submetidos a testes, sendo recompensados, caso alcancem os resultados esperados, ou punidos, se não atenderem às normas.

\footnotetext{
${ }^{7}$ Não faz distinção de sexo, gênero, raça, cor ou classe social.

${ }^{8}$ Não é facultada à criança ou ao jovem.
} 
Nessas circunstâncias, a equipe de profissionais que compõe a escola, especialmente o professor, inserto no cotidiano do estudante, pode adotar duas atitudes conflitantes: primeiro, atuando como vigilante incansável na busca da padronização de comportamentos e conteúdo e, na sequência, estimulando em seus alunos o pensamento que ultrapassa a mera conformação. Esses profissionais, no entanto, também estão inseridos numa relação de poder e dominação, na medida em que se veem obrigados a vender a sua força de trabalho em troca dos salários, sendo, portanto, vigiados e controlados diretamente por seus superiores (os capitalistas donos da escola ou o Estado) e por meio de normas, decretos e leis que conduzem a sua prática e não permitem grandes mobilidades. Esses trabalhadores são, todavia, potencial e contraditoriamente, importantes na elaboração de resistências, na perspectiva da formação integral dos sujeitos, reunindo conhecimento intelectual à instrução tecnológica, ao esporte e à cultura, permitindo reflexão crítica acerca do movimento histórico do real, elucidando, desde aí, a subordinação, a alienação e exploração a que se submetem o jovem e o adulto.

Em contrapartida, o que se pretende com a recente reforma do Ensino Médio é desarticular o conhecimento e reafirmar a escola como um aparelho a serviço dos interesses de grupos dominantes brasileiros, sendo utilizada para disseminar a sua ideologia e introjetar nos indivíduos o sentimento de culpa pelos fracassos pessoais e de inevitável submissão ao modo de produção capitalista.

Isto posto, asseveramos que esta reforma é expressão das disputas em torno de projetos distintos de formação dos jovens, em que frações sociais, defensoras da Educação integral e emancipatória, se enfraqueceram na realidade política, permitindo a aprovação de um modelo sonegador do direito dos trabalhadores ao conhecimento, à autonomia, bem como à sua elevação cultural.

\section{REFERÊNCIAS}

ANDES. A contrarreforma do Ensino Médio: o caráter excludente, pragmático e imediatista da Lei 11.715/2017. Brasília, Andes, 2017. Disponível em: http://portal.andes.org.br/imprensa/documentos/imp-doc-1049083919.pdf. Acesso em: 4 set. 2019.

ANDRADE, Luma Nogueira. Travestis na escola: assujeitamento e resistência à ordem normativa. 2012. 278 f. Tese (Doutorado em Educação) - Programa de PósGraduação em Educação, Faculdade de Educação, Universidade Federal do Ceará, Fortaleza, 2012.

ANFOPE. Políticas de formação e valorização dos profissionais da Educação: (contra) reformas e resistências. XIX ENCONTRO NACIONAL DA ANFOPE, Niterói, Univesidade Federal Fluminense, 2018. Disponível em: http://www.anfope.org.br/wpcontent/uploads/2018/11/XIX-Encontro-2018.pdf. Acesso em: 4 set. 2019. 
ANPOCS. Nota pública pela revogação da Lei da reforma do Ensino Médio MP. 13.475/2017 e retirada da proposta de BNCC apresentada em 2018. Disponível em: https://www.anpocs.com/index.php/ciencias-sociais/destaques/1900-entidadeslancam-nota-publica-solicitando-revogacao-da-reforma-do-ensino-medio-e-retiradada-proposta-da-bncc. Acesso em: 4 set. 2019.

ARAÚJO, Adilson Cesar; SILVA, Cláudio Nei Nascimento. Ensino Médio Integrado no Brasil: fundamentos, práticas e desafios. Brasília, IFB, 2017. Disponível em: http://www.anped.org.br/sites/default/files/images/livro_completo_ensino_medio_inte grado_-_13_10_2017.pdf. Acesso em: 9 set. 2019.

ARROYO, Miguel González. Apresentação. In: SOUZA, Francisco das Chagas Silva; NUNES, Albino Oliveira. Temas em Educação Profissional. Rio de Janeiro, Editora Essentia, 2019.

BRANCO, Verônica. Desafios para a implantação da Educação Integral: análise das experiências desenvolvidas na região sul do Brasil. Educ. rev. nํ. 45. Curitiba Jul/Set. 2012. Disponível em:

https://revistas.ufpr.br/educar/article/viewFile/30009/19393. Acesso em: 30 mar. 2020.

BRASIL. Lei no 10.172, de 9 de janeiro de 2001. Aprova o Plano Nacional de Educação e dá outras providências. Brasília, 2001.Disponível em:

http://www.planalto.gov.br/ccivil_03/leis/leis_2001//10172.htm. Acesso em: 30 mar. 2020.

BRASIL. Lei no 13.005, de 25 de junho de 2014. Aprova o Plano Nacional de Educação e dá outras providências. Brasília, 2014. Disponível em:

http://www.planalto.gov.br/ccivil_03/_ato2011-2014/2014/lei/l13005.htm. Acesso em: 30 mar. 2020.

BRASIL. Lei no 13.415, de 16 de fevereiro de 2017. Institui a Política de Fomento à Implementação de Escolas de Ensino Médio em Tempo Integral. Brasília, DF:

Presidência da República, [2017]. Disponível em:

http://www.planalto.gov.br/ccivil_03/_Ato2015-2018/2017/Lei/L13415.htm. Acesso em: 19 mar. 2019.

CAVALCANTI, Erinaldo Vicente. A história encastelada e o Ensino encurralado: reflexões sobre a formação docente dos professores de história. Educar em revista, v. 34, n. 72, 2018. Disponível em:

http://www.scielo.br/scielo.php?script=sci_arttext\&pid=S0104-

$40602018000600249 \&$ Ing=pt\&nrm=iso\&tIng=pt. Acesso em: 4 set. 2019.

\section{CALLEGARI, César. Carta aos conselheiros do Conselho Nacional de}

Educação. Brasília, 2018. Disponível em: http://www.epsjv.fiocruz.br/carta-aosconselheiros-do-conselho-nacional-de-educacao-cesar-callegari-renuncia-apresidencia-da. Acesso em: 4 set. 2019.

CIAVATTA, Maria. A cultura do trabalho e a Educação plena negada. Fortaleza, Revista Labor, v.1, n.5, 2011. Disponível em:

http://www.periodicos.ufc.br/labor/issue/view/492. Acesso em: 04 set. 2019. 
CNTE. Dossiê reforma do Ensino Médio. Brasília, CNTE, Retratos da Educação, V. 11, n. 20, 2017. Disponível em:

https://cnte.org.br/images/stories/retratos_da_escola/retratos_da_escola_20_2017.p df. Acesso em: 4 set. 2019.

COSTA, Maria Adélia; COUTINHO, Eduardo Henrique Lacerda. Educação profissional e a reforma do Ensino Médio. Porto Alegre, Revista Educação e Realidade., v. 43, n. 4, 2018. Disponível em: http://www.scielo.br/scielo.php?script=sci_arttext\&pid=S2175-62362018000401633. Acesso em: 16 set. 2019.

ENGUITA, Mariano Fernandez. A face oculta da escola: educação e trabalho no capitalismo. Tradução: Tomaz Tadeu da Silva. Porto Alegre: Artes Médicas, 1989.

FERRETTI, Celso João. A reforma do Ensino Médio e sua questionável concepção de qualidade da Educação. São Paulo, Estudos Avançados, v. 32, n. 93, 2018. Disponível em: http://www.scielo.br/scielo.php?script=sci_arttext\&pid=S010340142018000200025. Acesso em: 4 set. 2019.

FOUCAULT, Michael. Vigiar e Punir. Tradução: Raquel Ramalhete. 20. ed. Petrópolis: Editora Vozes, 1999.

FREIRE, Paulo. Pedagogia do oprimido. 17. ed. Rio de Janeiro: Paz e Terra, 1987. LIMA, Marcelo; MACIEL, Samanta Lopes. A reforma do Ensino Médio do governo Temer: corrosão do direito à educação no contexto de crise do capital no Brasil. Revista Brasileira de Educação. Rio de Janeiro, v. 23, pp. 01-25, out. 2018. Disponível em: http://www.scielo.br/pdf/rbedu/v23/1809-449X-rbedu-23-e230058.pdf. Acesso em: 30 ago. 2019.

MÉSZÁROS, István. A educação para além do capital. Tradução: Isa Tavares. 2. Ed. São Paulo: Boitempo, 2008.

MOTTA, Vânia Cardoso; FRIGOTTO, Gaudêncio. Por que a urgência da reforma do ensino médio? Medida Provisória № 746/2016 (Lei № 13.415/2017). Educação \& Sociedade, v. 38, oㅡ 139, pp. 355-372, abr.-jun., 2017. Disponível em: http://www.scielo.br/pdf/es/v38n139/1678-4626-es-38-139-00355.pdf. Acesso em: 13 set. 2019.

NOSELLA, Paolo; SILVA, Luciane Teixeira da. A cultura extrema enquanto estratégia de hegemonia: uma análise a partir dos escritos de Antônio Gramsci. Revista Labor, n. 22, v.1, 2019. Disponível em: http://www.periodicos.ufc.br/labor/article/view/42630/100355. Acesso em: 18 fev. 2020.

OLIVEIRA, Elenilce Gomes. A "personalidade vigorosamente formada", em Gramsci, e obstáculos no âmbito do ensino médio. Holos, Natal, v. 6, pp. 178-187, 2016. Disponível em: http://www2.ifrn.edu.br/ojs/index.php/HOLOS/article/view/4996/1576. Acesso em: 21 jul. 2017

RAMOS, Marise Nogueira; FRIGOTTO, Gaudêncio. Medida Provisória 746/2016: a contrarreforma do ensino médio do Golpe de Estado de 31 de agosto de 2016.

Revista HISTEDBR On-line, Campinas, ํo 70, pp. 30-48, dez. 2016. Disponível em: 
https://periodicos.sbu.unicamp.br/ojs/index.php/histedbr/article/view/8649207/15754 . Acesso em: 13 set. 2019.

SAVIANI, Dermeval. Trabalho e educação: fundamentos ontológicos e históricos.

Revista Brasileira de Educação, v. 12, n. 34, pp. 152-180, jan./abr. 2007.

Disponível em: http://www.scielo.br/pdf/rbedu/v12n34/a12v1234.pdf. Acesso em: 24 jun. 2018.

SILVA, Valdelice Barbosa da; NUNES, Karla Lécia Barros; SILVA, Thamyres Ferreira da; SILVA, Vitória Carolina Santos. Educação e reprodução social: um estudo sócio-histórico de seu processo. In: CONGRESSO NACIONAL DE EDUCAÇÃO, 5., 2018, Olinda. Anais [...] Olinda, 2018. Disponível em: http://www.editorarealize.com.br/revistas/conedu/trabalhos/TRABALHO_EV117_MD 1_SA4_ID5000_17092018213109.pdf. Acesso em: 09 nov. 2019.

SINSEJ. Pela revogação total da BNCC e da reforma do ensino. Disponível em: http://www.sinsej.org.br/2018/07/pela-revogacao-total-da-bncc-e-da-reforma-ensino/. Acesso em 4 set. 2019.

SINPRO. Sintet e Sinpro são contra reforma do Ensino. Disponível em: http://www.sinsej.org.br/2018/07/pela-revogacao-total-da-bncc-e-da-reforma-ensino/. Acesso em: 4 set. 2019. 